\title{
Dog bite injuries in the USA: prevalence, correlates and recent trends
}

\author{
Katherine J Holzer, Michael G Vaughn, Vithya Murugan
}

School of Social Work, College for Public Health and Social Justice, Saint Louis University, St Louis, Missouri, USA

\section{Correspondence to} Katherine J Holzer, School of Social Work, College for Public Health and Social Justice, Saint Louis University, St. Louis, MO 63103, USA; katie.holzer@ slu.edu

Received 25 May 2018 Revised 2 July 2018 Accepted 6 July 2018 Published Online First 23 July 2018

Check for updates

(c) Author(s) (or their employer(s)) 2019. No commercial re-use. See rights and permissions. Published by BMJ.

To cite: Holzer KJ, Vaughn MG, Murugan V. Inj Prev 2019;25:187-190.

\section{ABSTRACT}

Dog bite-related injuries are associated with high medical costs. The aim of this study was to estimate the prevalence, correlates and recent trends in dog bite injuries among male and female individuals presenting to US emergency departments. The prevalence of dog bites was calculated for years 2010-2014 using the Nationwide Emergency Department Sample. Sexstratified multivariate logistic regression analyses were conducted with 'dog bite' as the dependent variable and patient and hospital characteristics as independent variables. Overall, the prevalence of dog bite injuries decreased from 2010 to 2014. The prevalence is highest in this sample among male youth. Male individuals diagnosed with an externalising behaviour disorder were more likely to present with a dog bite $(\mathrm{OR}=1.21,95 \% \mathrm{Cl} 1.27$ to 1.30$)$. While the prevalence of dog bites has decreased in recent years, this costly and largely preventable injury remains a concern, especially among youth.

\section{INTRODUCTION}

Approximately $36 \%$ of households in the USA have at least one dog. ${ }^{1}$ Dog bites account for a majority of animal bites in the USA ${ }^{2}$ and are most likely to involve a dog in the home or one known to the family. ${ }^{3}$ Dog bite-related injuries are associated with high medical costs. A significant number of individuals presenting to hospital emergency departments (ED) for dog bite injuries are hospitalised, requiring surgical procedures and extended pharmaceutical treatment. ${ }^{4}$ It is estimated that the annual cost of dog bites is approximately $\$ 165$ million. ${ }^{5}$ Complications associated with these injuries include nerve damage, pain, infection ${ }^{167}$ and death. ${ }^{89}$

Research into the incidence of dog bites consistently finds that the rate of dog bite injuries is higher among children, especially boys aged 5-9 years. ${ }^{10} 11$ From 2005 to 2009 , the estimated average annual injury rate of non-fatal dog bites treated in US EDs was 107.2 per 100000 population, with boys accounting for $53 \%$ of the injuries and the highest rates observed among children ages 5-9 years. ${ }^{10}$ The increased prevalence among children is especially troubling given that this population appears to have the highest rates of serious injury from dog bites. $^{12}{ }^{13}$ Multiple studies investigating fatal dog bites find that the majority of victims are children. ${ }^{89}$

An examination of recent trends in dog bite injuries as well as victim characteristics provides an empirical basis for focused prevention and intervention efforts. While some surveillance efforts were conducted at the national level in the past, the majority of current research in this area is conducted outside of the USA or with state-specific samples. ${ }^{614}$ Previous research suggests that the use of ED data is an economical and sustainable approach to surveillance of dog bite injuries in the USA, ${ }^{14}$ especially when examining trends over time. The current study uses population-based, cross-sectional data from the Nationwide Emergency Department Sample (NEDS) to examine the prevalence, correlates and recent trends in dog bite injuries among male and female individuals presenting to US EDs between 2010 and 2015.

\section{METHODS}

This study employed data from the 2010-2015 NEDS from the Healthcare Cost and Utilization Project (HCUP) distributed by the US Department of Health and Human Services Agency for Healthcare Research and Quality (AHRQ). ${ }^{15}$ The NEDS sampling frame is limited to hospital-owned EDs in the 34 states and District of Columbia for which HCUP ED data are available through the State Inpatient Databases (patients initially seen in the ED and admitted to the same hospital) and State Emergency Department Databases (ED visits that are not admitted to the same hospital). Sample stratification was based on geographical region, trauma centre designation, urban-rural location of the hospital, teaching hospitals and hospital ownership. The NEDS contains data on approximately 31 million hospital-based ED visits from 953 hospitals, approximating a $20 \%$ stratified sample of US hospital-owned EDs. The HCUP provides hospital and discharge weights to calculate national estimates of approximately 143 ED visits. The data contain demographic information including hospital and patient characteristics, geographical region and reason for ED visit, as well as ED charge information.

While the study used data from 2010 to 2015, the International Classification of Diseases, 10th Revision, Clinical Modification (ICD-10-CM) became effective on 1 October 2015, and therefore patients discharged after this time were excluded from the analytic sample to ensure comparable measurement of dog bites from 2010 to 2015 (quarters 1 through 3 ).

\section{Dog bite}

For 2010 through quarter 3 of 2015 (discharges from 1 January 2015 to 30 September 2015), ED discharges with the primary ICD-9-CM external cause of injury code (ECODE1) of E906.0 (dog bite) were identified as a dog bite discharge. 


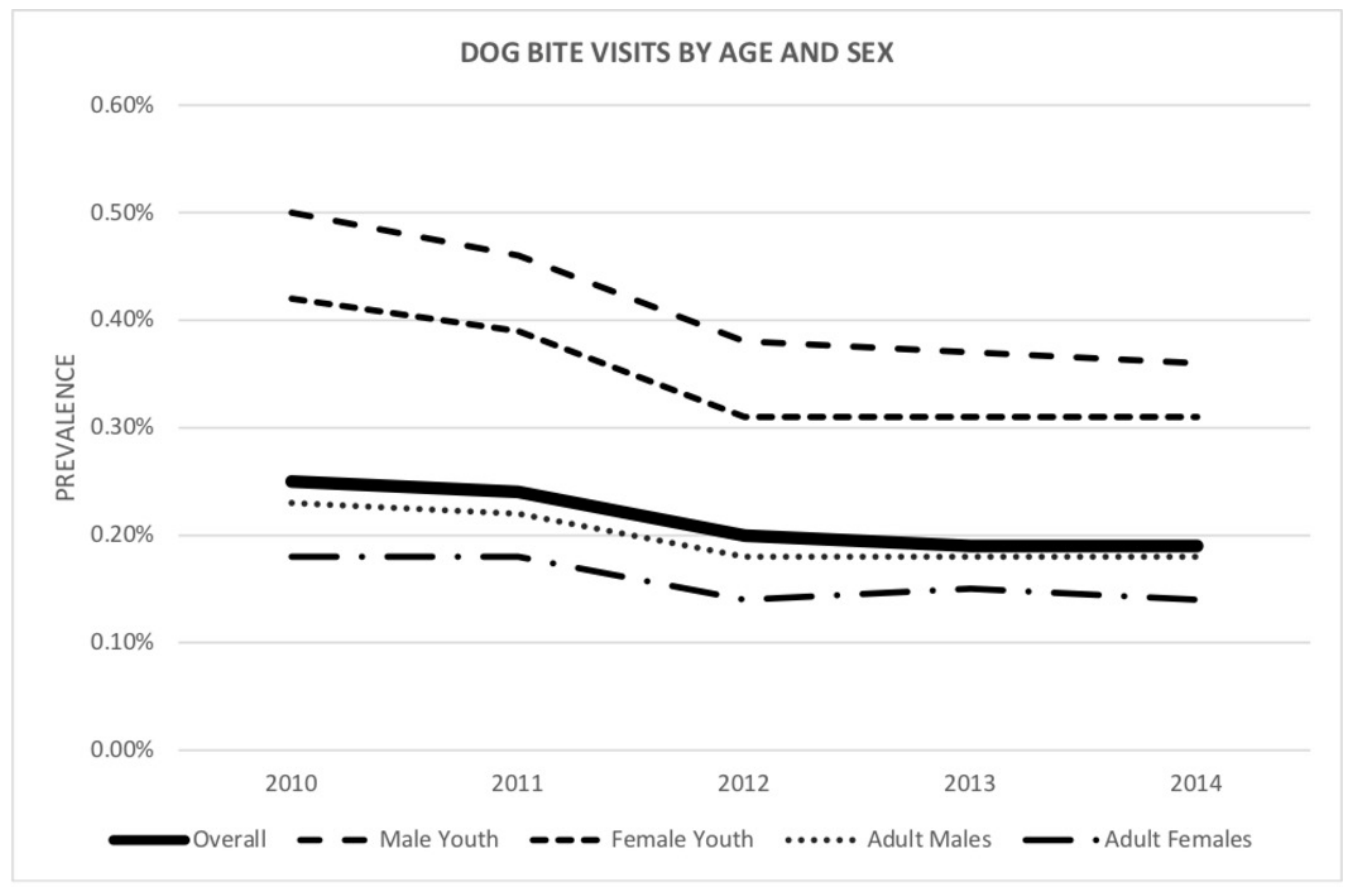

Figure 1 Prevalence estimates for dog bite injuries among US emergency department discharges: by age and sex.

\section{Hospital and patient covariates}

Patient characteristics included sex, age in years $(<18,18-25$, 26-35, 36-50 and >50), median household socioeconomic status in quartiles designated by the patient's zip code, primary payer (Medicare, Medicaid, private insurance, self-pay, no charge, and others including worker's compensation, Civilian Health and Medical Program of the Uniformed Services, Civilian Health and Medical Program of the Department of Veterans Affairs, Title V, and other government programmes) and admission day (Monday-Friday or Saturday-Sunday). Hospitals were characterised by region (West, Northeast, Midwest or South). Additionally, the ICD-9-CM clinical classification category codes (DXCCS1-DXCCS15) developed by the AHRQ to cluster patient diagnoses were used to identify patients diagnosed with attention-deficit, conduct and disruptive behaviour disorders (code 652), and examined as a dichotomous independent variable $(0=$ no diagnosis, $1=$ diagnosis $)$.

\section{Statistical analysis}

After identifying dog bite cases for 2010-2015 ( $\mathrm{n}=372$ 597), random sampling (10\% of non-dog bite cases) was used to identify non-dog bite discharges $(n=3433285)$ for comparison purposes. The use of random sampling is common for this data source due to the intense computation demands of working with such a large number of cases. ${ }^{16}$ Following sample identification, the prevalence of dog bites was calculated for years 2010-2014. Due to the coding change occurring in the fourth quarter of 2015, prevalence estimates from this year were not comparable with the previous years and eliminated from the trend analysis. Data for 2015 were excluded from prevalence estimates due to the coding change occurring in the fourth quarter. Sex-stratified multivariate logistic regression analyses were conducted with 'dog bite' as the dependent variable and patient and hospital characteristics as independent variables. Analyses accounted for the single-stage cluster sampling design specific to the NEDS using Stata's svy commands, with the hospital and discharge weight variables provided by the HCUP (Stata Corp, 2015).

\section{RESULTS}

Trends in prevalence of dog bite injuries admitted to the ED

Figure 1 displays the prevalence estimates of dog bite injuries admitted to the ED among youth $($ age $<18)$ and adults $($ age $\geq 18)$ by sex. Overall, the prevalence of dog bite injuries decreased from $0.25 \%$ in 2010 to $0.19 \%$ in 2014 . For each year, the prevalence of dog bite injuries is highest among youth, with male youth consistently having the highest prevalence and adult women with the lowest prevalence compared with the other age/ sex groups each year.

\section{Characteristics of dog bite victims}

Table 1 presents the demographic characteristics of dog bite victims admitted to the ED stratified by sex. For both male and female individuals, the odds of a dog bite injury were highest for the youngest age group (male: $<18$, OR $=2.96$, 95\% CI 2.87 to 3.05 ; female: $<18, \mathrm{OR}=2.41,95 \% \mathrm{CI} 2.34$ to 2.48 ), patients admitted on a weekend (male: $\mathrm{OR}=1.28,95 \%$ CI 1.27 to 1.30 ; female: $\mathrm{OR}=1.27,95 \%$ CI 1.25 to 1.28 ), those using a non-Medicare insurance as their primary payer, patients admitted to hospitals in the Northeast (male: OR $=1.27,95 \%$ CI 1.18 to 1.37 ; female: $\mathrm{OR}=1.47,95 \%$ CI 1.36 to 1.58 ) and patients residing in a zip code with a higher median household income (76th-100th percentile, male: $\mathrm{OR}=1.20,95 \%$ CI 1.16 to 1.25 ; female: $\mathrm{OR}=1.59,95 \%$ CI 1.53 to 1.65$)$. For age, the association with dog bites was stronger among male individuals. Boys younger than 18 were three times more likely $(\mathrm{OR}=2.96,95 \% \mathrm{CI} 2.87$ to 3.05$)$ than adults over the age of 50 years to experience a dog bite, and men 18-25 were twice as likely $(\mathrm{OR}=1.98,95 \% \mathrm{CI} 1.93$ to 2.03$)$. Girls younger than 18 were 2.41 times more likely $(95 \%$ CI 2.34 to 2.48$)$ to have a dog bite injury than adults over the age of 50 , and women ages 18-25 were only 1.09 times as likely (95\% CI 1.07 to 1.12). Similarly, a diagnosis of an externalising behaviour disorder (attention-deficit, conduct and/or disruptive behaviour disorder) was significantly related to dog bites among male individuals 
Table 1 Demographic characteristics of dog bite victims compared with non-dog bite victims according to sex

\begin{tabular}{|c|c|c|c|c|c|c|}
\hline & OR & $95 \% \mathrm{Cl}$ & $P$ values & OR & $95 \% \mathrm{Cl}$ & $P$ values \\
\hline \multicolumn{7}{|l|}{ Age (years) } \\
\hline$>50(\mathrm{M}=536976 ; \mathrm{F}=675$ 483) & Reference & & & Reference & & \\
\hline $36-50(M=319934 ; F=395$ 511) & 1.55 & 1.51 to 1.58 & $<0.001$ & 1.32 & 1.29 to 1.34 & $<0.001$ \\
\hline $26-35(M=233732 ; \mathrm{F}=333774)$ & 1.81 & 1.77 to 1.85 & $<0.001$ & 1.04 & 1.02 to 1.06 & $<0.001$ \\
\hline $18-25(M=195044 ; F=302727)$ & 1.98 & 1.93 to 2.03 & $<0.001$ & 1.09 & 1.07 to 1.12 & $<0.001$ \\
\hline$<18(\mathrm{M}=429791 ; \mathrm{F}=382530)$ & 2.96 & 2.87 to 3.05 & $<0.001$ & 2.41 & 2.34 to 2.48 & $<0.001$ \\
\hline \multicolumn{7}{|l|}{ Primary payer } \\
\hline Medicare (M=338 444; $F=456$ 338) & Reference & & & Reference & & \\
\hline Medicaid (M=448 215; F=642 329) & 2.57 & 2.49 to 2.64 & $<0.001$ & 1.61 & 1.57 to 1.65 & $<0.001$ \\
\hline Private insurance $(\mathrm{M}=501$ 294; $\mathrm{F}=606$ 859) & 3.06 & 2.98 to 2.13 & $<0.001$ & 2.73 & 2.66 to 2.79 & $<0.001$ \\
\hline Self-pay (M=309 928; $F=279$ 887) & 2.69 & 2.59 to 2.79 & $<0.001$ & 1.98 & 1.92 to 2.04 & $<0.001$ \\
\hline No charge $(M=12888 ; F=12358)$ & 2.03 & 1.87 to 2.20 & $<0.001$ & 1.63 & 1.49 to 1.78 & $<0.001$ \\
\hline Other $(\mathrm{M}=100232 ; \mathrm{F}=87 \mathrm{865})$ & 3.39 & 3.25 to 3.54 & $<0.001$ & 3.19 & 3.04 to 3.35 & $<0.001$ \\
\hline \multicolumn{7}{|l|}{ Externalising behaviour } \\
\hline No diagnosis ( $M=1700$ 999; $F=2080$ 818) & Reference & & & Reference & & \\
\hline Diagnosis $(\mathrm{M}=14537 ; \mathrm{F}=9278)$ & 1.21 & 1.14 to 1.29 & $<0.001$ & 1.00 & 0.92 to 1.09 & 0.979 \\
\hline \multicolumn{7}{|l|}{ Admission day } \\
\hline Monday-Friday ( $M=1215$ 274; F=1 489 682) & Reference & & & Reference & & \\
\hline Saturday-Sunday (M=499 801; $F=600$ 093) & 1.28 & 1.27 to 1.30 & $<0.001$ & 1.27 & 1.25 to 1.28 & $<0.001$ \\
\hline \multicolumn{7}{|l|}{ Region of hospital } \\
\hline West ( $M=323$ 194; $F=376$ 375) & Reference & & & Reference & & \\
\hline Northeast (M=324 384; F=372 785) & 1.27 & 1.18 to 1.37 & $<0.001$ & 1.47 & 1.36 to 1.58 & $<0.001$ \\
\hline Midwest ( $M=346$ 276; $F=425$ 434) & 1.14 & 1.05 to 1.24 & 0.002 & 1.15 & 1.06 to 1.25 & $<0.001$ \\
\hline South $(M=721682 ; F=915502)$ & 1.23 & 1.15 to 1.31 & $<0.001$ & 1.16 & 1.08 to 1.24 & $<0.001$ \\
\hline \multicolumn{7}{|l|}{ Median household income for zip code } \\
\hline 0-25th percentile $(\mathrm{M}=562869 ; \mathrm{F}=699015)$ & Reference & & & Reference & & \\
\hline 26th-50th percentile $(M=445038 ; \mathrm{F}=551726)$ & 1.07 & 1.05 to 1.10 & $<0.001$ & 1.19 & 1.16 to 1.22 & $<0.001$ \\
\hline 51st-75th percentile $(M=375737 ; F=459147)$ & 1.12 & 1.08 to 1.15 & $<0.001$ & 1.30 & 1.26 to 1.34 & $<0.001$ \\
\hline 76th-100th percentile ( $M=293006 ; \mathrm{F}=341$ 933) & 1.20 & 1.16 to 1.25 & $<0.001$ & 1.59 & 1.53 to 1.65 & $<0.001$ \\
\hline
\end{tabular}

Externalising behaviour includes diagnosis for attention-deficit, conduct and disruptive behaviour disorders (code 652 for Clinical Classifications Software values 1-15). Source: National Emergency Department Surveillance ${ }^{26}-2015$ (Q1-Q3).

$\mathrm{F}$, female; M, male.

$(\mathrm{OR}=1.21,95 \%$ CI 1.27 to 1.30$)$, but not among female individuals $(\mathrm{OR}=1.00,95 \% \mathrm{CI} 0.92$ to 1.09$)$.

\section{DISCUSSION}

Our findings indicate a decrease in dog bite injuries from 2010 to 2014. We observed age and sex differences in that the prevalence is higher among youth, especially male youth. Additionally, there was an association between diagnosis of a behaviour disorder and dog bites among male individuals, supporting recent research findings that patients diagnosed with attention-deficit hyperactivity disorder (ADHD) are at an elevated risk of dog bites and risk of postbite complications. ${ }^{17}$ The findings regarding dog bites, specifically, are consistent with previous studies indicating an increased risk of any injury among children diagnosed with externalising behavioural disorders. ${ }^{18-21}$ While these studies do not identify potential causal mechanisms involved in this relationship, the results of one study suggest that boys with ADHD associate risky behaviour with less severe consequences and report fewer methods for injury prevention compared with controls. ${ }^{19}$ Given that most dog-related injuries are linked to child-initiated interactions with dogs, future research should explore specific behaviours and additional symptoms of externalising behaviour disorders that may be associated with a greater risk for injury.

The absence of a significant association between externalising behaviour disorders and dog bites among female individuals is consistent with research finding that male individuals are more likely to be diagnosed with these disorders, engage in externalising behaviours to a greater degree, and their behaviour disorder symptoms tend to be more severe than female individuals. ${ }^{22-24}$ This, coupled with the smaller sample size for female individuals, likely accounts for the relative lack of significance found among female individuals.

While the prevalence of dog bites has decreased in recent years, this costly and largely preventable injury remains a concern. Patronek and colleagues ${ }^{8}$ revealed that most of the incidents are characterised by preventable factors, including failure to neuter and owners' history of abuse or neglect of dogs involved in biting incidents, as well as the absence of able-bodied persons to intervene. Approximately $86 \%$ of dog-related injuries at home are triggered by child-initiated interactions with the dogs. ${ }^{25}$ There are a number of recommended prevention practices easily employed by dog owners to reduce the risk of dog bites as well as prevent a bite from escalating. ${ }^{2}$ Recent research suggests that video-based interventions targeting children ages 5-9 years may effectively increase their knowledge of dog bite prevention. ${ }^{26}$

\section{Study limitations}

The results from the current study only represent victims of dog bite injuries presenting to the ED. The estimates suggest that only $10 \%-50 \%$ of dog bite injuries are reported. ${ }^{6}$ It is likely that there are significant differences between individuals who seek treatment for bites at the ED and those who seek treatment 
elsewhere, if at all. Additionally, while data were pooled from 2010 through 2015, the NEDS data are cross-sectional and therefore limit our ability to draw causal inferences. Despite these limitations, the present study provides a useful examination of trends in dog bites in the US population.

\section{What is already known on the subject}

- Dog bites account for a majority of animal bites in the USA and are more likely to involve a dog in the home or one known to the family.

- Dog bite-related injuries are associated with high medical costs.

- The rate of dog bites is higher among children.

\section{What this study adds}

- Overall, the prevalence of dog bite injuries decreased from 2010 to 2014.

- The prevalence of dog bites is highest among youth, especially male youth.

- There was an association between diagnosis of a behaviour disorder and dog bites in male individuals.

Contributors There were no contributors who did not meet the criteria for authorship.

Funding The authors have not declared a specific grant for this research from any funding agency in the public, commercial or not-for-profit sectors.

Competing interests None declared.

Patient consent Not required.

Ethics approval The NEDS is considered a 'limited dataset' under the HIPAA Privacy Rule and contains no direct patient identifiers; therefore, the current study did not require review from an institutional review board.

Provenance and peer review Not commissioned; externally peer reviewed.

\section{REFERENCES}

1 Centers for Disease Control and Prevention. Preventing dog bites. 2018. https://www. cdc.gov/features/dog-bite-prevention/index.html (accessed 16 May 2018).

2 Ellis R, Ellis C. Dog and cat bites. Am Fam Physician 2014;90:239-43.

3 Beck AM, Jones BA. Unreported dog bites in children. Public Health Rep 1985; 100:315-21.
4 Quinlan KP, Sacks JJ. Hospitalizations for dog bite injuries. JAMA 1999;281:232-3.

5 Esposito S, Picciolli I, Semino M, et al. Dog and cat bite-associated infections in children. Eur J Clin Microbiol Infect Dis 2013;32:971-6.

6 Pfortmueller CA, Efeoglou A, Furrer $\mathrm{H}$, et al. Dog bite injuries: primary and secondary emergency department presentations-a retrospective cohort study. ScientificWorldJournal 2013:2013:1-6.

7 Stiegler D, Gilbert JD, Warner MS, et al. Fatal dog bite in the absence of significant trauma: Capnocytophaga canimorsus infection and unexpected death. Am J Forensic Med Pathol 2010:31:198-9.

8 Patronek GJ, Sacks JJ, Delise KM, et al. Co-occurrence of potentially preventable factors in 256 dog bite-related fatalities in the United States (2000-2009). J Am Vet Med Assoc 2013;243:1726-36.

9 Sacks JJ, Sattin RW, Bonzo SE. Dog bite-related fatalities from 1979 through 1988. JAMA 1989;262:1489-92.

10 Quirk JT. Non-fatal dog bite injuries in the U.S.A., 2005-2009. Public Health 2012;126:300-2.

11 Weiss HB, Friedman DI, Coben JH. Incidence of dog bite injuries treated in emergency departments. JAMA 1998;279:51-3.

12 Horswell BB, Chahine CJ. Dog bites of the face, head and neck in children. W V Med J 2011;107:24-7.

13 Ozanne-Smith J, Ashby K, Stathakis VZ. Dog bite and injury prevention--analysis, critical review, and research agenda. Inj Prev 2001;7:321-6.

14 Bregman B, Slavinski S. Using emergency department data to conduct dog and animal bite surveillance in New York City, 2003-2006. Public Health Rep 2012;127:195-201.

15 HCUP Nationwide Emergency Department Sample (NEDS). Healthcare Cost and Utilization Project (HCUP). Rockville, MD: Agency for Healthcare Research and Quality, 2015.

16 Beydoun HA, Williams M, Beydoun MA, et al. Relationship of physical intimate partner violence with mental health diagnoses in the nationwide emergency department sample. J Womens Health 2017;26:141-51.

17 Mitchell RB, Nañez G, Wagner JD, et al. Dog bites of the scalp, face, and neck in children. Laryngoscope 2003;113:492-5.

18 Brehaut JC, Miller A, Raina P, et al. Childhood behavior disorders and injuries among children and youth: a population-based study. Pediatrics 2003;111:262-9.

19 Farmer JE, Peterson L. Injury risk factors in children with attention deficit hyperactivity disorder. Health Psychol 1995;14:325-32.

20 Nigg JT. Attention-deficit/hyperactivity disorder and adverse health outcomes. Clin Psychol Rev 2013;33:215-28.

21 van den Ban E, Souverein P, Meijer W, et al. Association between ADHD drug use and injuries among children and adolescents. Eur Child Adolesc Psychiatry 2014;23:95-102

22 Eme R. Male life-course-persistent antisocial behavior: the most important pediatric mental health problem. Arch Pediatr Adolesc Med 2010;164:486-7.

23 Moffitt TE. Male antisocial behaviour in adolescence and beyond. Nat Hum Behav 2018;2:177-86.

24 Willcutt EG. The prevalence of DSM-IV attention-deficit/hyperactivity disorder: a metaanalytic review. Neurotherapeutics 2012;9:490-9.

25 Meints K, Racca A, Hickey N. How to prevent dog bite injuries? Children misinterpret dogs facial expressions. Injury Prevention 2010;16(Suppl 1):A68.

26 Dixon CA, Pomerantz WJ, Hart KW, et al. An evaluation of a dog bite prevention intervention in the pediatric emergency department. J Trauma Acute Care Surg 2013:75(Suppl 3):S308-12. 